\title{
Antioxidant Activity and Proximate Analysis of Alaagoal Ethanolic Extract in Gentamicin Toxicated Rats
}

\author{
Hala Elrayah Ahmed ${ }^{1 *}$, Samia Hussein Abdlrahman ${ }^{1}$, Salwa Mohamed Elbasheir ${ }^{1}$, Sara Ahmed Mohamed ${ }^{1}$ \\ and Samia Mohamed Elbadwi ${ }^{2}$
}

${ }^{1}$ Central Veterinary Research laboratory, UAE

${ }^{2}$ Department of Pharmacology and Toxicology, Faculty of Veterinary Medicine, University of Khartoum, Sudan

*Corresponding author: Hala Elrayah Ahmed, Central Veterinary Research laboratory, UAE.

Received Date: January 29, 2020

Published Date: February 20, 2020

\section{Abstract}

Plants are the most important source of medicine to the mankind. Ancient and traditional verbal as well as documented sources are treasure of potential medicinal properties of plants. In the new era of science and technology there is increasing need to validate the claims of traditional knowledge database for safe, easily available, cheap, side-effect free healthcare provisions. Some species from the genus Fagonia are supposed to possess important medicinal properties. In this article the proximate analysis and antioxidant activity (In vivo) of Alaagoul (Fagonia cretica L) ethanolic extract was evaluated. The proximate analysis for the ethanolic extract of Alaagoul (Fagonia cretica L) demonstrated: Moisture 3.0\%, Ash 14.0\%, protein $27.84 \%$, Ether extracts $2.3 \%$, Fiber 19.0\%, Nitrogen free extract 33.86\%, Energy 238.6.The administration of Fagonia cretica $L$ ethanolic extract followed by gentamicin improved the activity of catalase and super oxide dismutase.

Keywords: Alaagoul; Antioxidant; Proximate analysis; Fagonia cretica $L$

\section{Introduction}

Plants and herbs have provided natural remedies for human ailments from time immortal. As knowledge progressed, man selected different herbs for cure of different diseases and ailments. The World Health Organization (WHO) estimated that about $80 \%$ of the world's population relies on traditional medicines for their primary health care. Most of the plants, which are used for various ailments, have not been properly investigated. About $30 \%$ of the pharmaceuticals are prepared from plants worldwide [1].

Alaagoul (Fagonia) is small, spiny, and erect, under shrubs, more and less granular, branches slander, terete, triate, glabrous. Leaves opposite, 1-3 foliate; petioles very variable in length, from 3 - $30 \mathrm{~mm}$ long, deeply striate, very slender; stipules 2 pairs of sharp slender thorns, sometimes exceeding $12 \mathrm{~mm}$ in length; leaflets linear, acute, sessile or with very short petiolules. It is branching herbs woody at the base, erect or prostrate [2]. Number of species like Fagonia cretica, Arabica, Bruguieri, Mysorensis, Indica, Schweinfurthii, Laevis, longispina etc. have been identified. Traditionally it is used in Sind and Afganistan as a popular remedy for fever among the hill people. The plant is given as a tonic and febrifuge, and in the Peshawar Valley it is given to children as a prophylactic against small- pox. The leaves and twigs are supposed to possess cooling properties. In the Ormara hills the plant is pounded and bound upon the swellings of the neck and for scrofula. At Saruna in Jhalawan it is pounded in water and strained; the liquid is rubbed all over the bodies of children when they get fever. In Kharan an infusion made with hot water is used as a bath in cases of fever. The plant is considered to cure for itch in the Las Bela State: and in the Levy tracts it is for that purpose pounded, mixed with milk, kept for three days and then rubbed all over the body [3]. Fagonia species were extensively studied by many workers regarding their medicinal uses, since these plants were antitumor, antioxidant, analgesic, astringent, febrifuge and prophylactic against small-pox agents. Species of Fagonia were also used for the treatment of cancer in the indigenous system, 
fever, asthma, urinary discharges, toothache, stomach troubles and kidney diseases. Species of Fagonia have been found to contain saponins, alkaloids, terpenoids, sterols, flavonoids, proteins and amino acids, coumarins, trace elements [4].

Antioxidants are group of chemicals that protect biological systems against the potential harmful effects of processes, or reactions that cause oxidation [5]. It was known that antioxidant in foods have many health benefits including prevention of various diseases associated with oxidative stress such as cancer, cardiovascular disease, neuro- degeneration and diabetes and others. However, there is a little knowledge of antioxidant activity in a variety of plants. There is strong evidence that reactive oxygen species including free radicals can lead to lipid peroxidation and oxidative stress which damage biological structures such as proteins, lipids and DNA [6]. They result in body ageing and chronic diseases such as heart disease, stroke, certain cancers, neurodegenerative diseases and lung disorders [7]. In general, the human body has its own natural antioxidant system to stand against free radicals using certain enzymes. It is believed that an intake of antioxidants reinforces the defense of human antioxidant system. Fruits, vegetables and spices are well known for their natural antioxidants. It has been found that high intake of fruits and vegetables has been associated with lower incidences of chronic diseases such as cancer and heart diseases [8]. Antioxidant activity of plants or fruits work in several mechanisms including free radical scavenging, hydrogen donation, singlet oxygen quenching, metal ion chelating and acting as a substrate for radicals such as super oxide and hydroxide.

\section{Materials and Methods}

\section{Plant materials}

Alaagoul Fagonia cretica $L$ was collected from North Sudan as a whole plant. The plant material was taxonomically identified and authenticated by taxonomy expert at Herbarium of Medicinal and Aromatic Plants Research Institute (MAPRI), National Center for Research (NCR), Khartoum, Sudan where the voucher specimen has been deposited.

\section{Animals}

Forty adult albino rats of either sexes weighing (100-120g) were divided into four groups each of 10 rats. The animals were either obtained from the experimental Animal house of the Central Veterinary Research Laboratory (Soba) and from the Faculty of Pharmacy University of Khartoum. They were housed at the experimental animal house at the Faculty of Pharmacy University of Khartoum. Animals were quarantined and observed for 7 days before the experiment. All animals were kept in aluminum laboratory cages; the animals were given the standard diet which is the normal pellet feed and freshwater ad libitum.

\section{Administration of doses}

After the adaptation animals were divided according to the weight into four groups each of 10 rats. Group I was given water and standard diet for 10 days and served as a control group. Group II was given gentamicin sulphate $80 \mathrm{mg} / \mathrm{kg} / \mathrm{d}$ (i.p.) from days 6 to 10.Group III was given Alaagoul (Fagonia cretica L) extract 250 $\mathrm{mg} / \mathrm{kg} / \mathrm{d}$ orally for 10 days and $80 \mathrm{mg} / \mathrm{kg} / \mathrm{d}$ gentamicin sulphate (GS) (i.p.) from day 6 to 10.Group IV was given Fagonia cretica $L$ extract $500 \mathrm{mg} / \mathrm{kg} / \mathrm{d}$ orally for 10 days and $80 \mathrm{mg} / \mathrm{kg} / \mathrm{d}$ gentamicin sulphate (GS) (i.p.) from day 6 to 10 .

\section{Parameters}

Blood samples from ocular vein were collected under light diethyl ether anesthesia into a sterile plain vacutainer tube at day 0,5 and 10 . Serum was separated by centrifugation for 15 minutes at 3000rpm and was kept under minus seventy percent to be tested for antioxidant.

\section{Preparation of (alaagoul) Fagonia cretica L ethanolic extract}

Ethanolic Extraction was carried out according to the method descried by [9]. Specific weight of each sample was grounded using mortar and pestle and extracted by soaking $80 \%$ ethanol for about seventy two hours with daily filtration and evaporation. Solvent was evaporated under reduced pressure to dryness using rotary evaporator apparatus and the extract allowed to air till complete dryness.

\section{Proximate analysis of alaagoul extract}

Estimation of moisture: Moisture was estimated according to the method described by [10].

Estimation of Ash: Ash was estimated according to the method of $[10,11]$.

Estimation of crude protein: Crude protein was determined according to the method described by $[11,12]$.

Estimation of crude fat: The method used to estimate crude fat value was described by [11].

Estimation of crude fiber: The crude fiber estimation was done according to the method described by [11].

Estimation of nitrogen free extracts (NFE): NFE contents of the samples were calculated by subtracting the percentages of moisture, ash, crude protein, crude fat, and crude fiber from 100 as below:

NFE $\%=100-($ moisture $\%+$ ash $\%+$ crude protein $\%+$ crude fat $\%+$ crude fiber $\%)$.

Metabolite energy calculation: The metabolite energy was calculated according to equation described by [13].

\section{Evaluation of antioxidant status in serum}

Determination of catalase (CAT) in serum: Catalase was determined in sera samples using commercial kits (Catalase (CAT) assay kit (visible light), A007-1, Nanjing Jiancheng Bioengineering Institute, Nanjing, China. spectrophotometric method. 
Determination of superoxide dismutase (SOD) in serum: Superoxide dismutase (SOD) was determined in sera samples using commercial kits (Superoxide dismutase (SOD) typed assay kit (Hydroxylamine method), A001-2, Nanjing Jiancheng Bioengineering Institute, Nanjing, China). spectrophotometric method.

Table 1: Proximate analysis of Fagonia cretica $L$ ethanolic extract.

\section{Results}

Proximate analysis of Fagonia cretica $L$. The proximate analysis of Alaagoul (Fagonia cretica L) Table 1, revealed that: Dry matter $97.0 \%$, Moisture 3.0\%, Ash 14.0\%, Crude protein 27.84\%, Ether extract $1.7 \%$, Crude fiber $19.0 \%$, Nitrogen free extract (N.F.E) 33.86 \%, Energy 233.3.

\begin{tabular}{|c|c|c|c|c|c|c|c|c|}
\hline Plant & DM \% & Moisture \% & Ash \% & Protein \% & E.E \% & Fiber \% & N.F.E \% & Energy \\
\hline Alaagoul (Fagonia) & 97.0 & 3.0 & 14 & 27.84 & 1.7 & 19 & 33.86 & 233.3 \\
\hline
\end{tabular}

\section{Antioxidant determination (In vitro)}

In our previous study, the antioxidant activity of Alaagoul ethanolic extract was evaluated in vitro, the percentage of radical scavenging activity in the extract equal (62\%).

\section{Antioxidant determination (in vivo)}

Serum catalase activity: Table 2 shows changes in catalase activity in serum of albino rats treated with (Fagonia cretica $L$ ) Alaagoul extract $(250,500 \mathrm{mg} / \mathrm{kg}$ B.W $)+$ gentamicin $(80 \mathrm{mg} / \mathrm{kg}$ B.W). At day 0, there was no significant changes observed in serum catalase activity in all groups when compared with group (A) the control group. At day 5, the activity of catalase in gentamicin group was significantly lower than the control group and it was lower in group D, but it was improved only in group C. At day 10 there was a significant decrease $(p>0.05)$ in Catalase activity in group B (gentamicin group) when compared with group A the control group, while there was a significant improvement observed in catalase activity in group C and D which given $(250$ and $500 \mathrm{mg} /$ $\mathrm{kg}$ B.W of Gubeish extract respectively) when compared with the control group (A) (Table 2).

Table 2: The activity of Catalase $(\mathrm{U} / \mathrm{ml})$ in rat's sera samples treated with Fagonia cretica at different doses.

\begin{tabular}{|c|c|c|c|}
\hline Group & Day 0 Mean \pm SE & $\begin{array}{c}\text { Day } 5 \text { Mean } \\
\pm \text { SE }\end{array}$ & Day 10 Mean \pm SE \\
\hline A & $15.01 \pm 1.06 \mathrm{a}$ & $14.36 \pm 1.07 \mathrm{~b}$ & $14.27 \pm 0.47 \mathrm{~b}$ \\
\hline B & $16.91 \pm 2.32 \mathrm{a}$ & $11.34 \pm 0.06 \mathrm{a}$ & $7.75 \pm 1.20 \mathrm{a}$ \\
\hline C & $13.51 \pm 0.28 \mathrm{a}$ & $13.87 \pm 0.00 \mathrm{~b}$ & $12.04 \pm 1.25 \mathrm{~b}$ \\
\hline D & $14.39 \pm 1.04 \mathrm{a}$ & $10.98 \pm 0.00 \mathrm{a}$ & $12.04 \pm 1.14 \mathrm{~b}$ \\
\hline
\end{tabular}

Means in the same column followed by the same letters are not significantly different at $(p>0.05)$.

$A=$ Negative control

$\mathrm{B}=$ Positive control (Gentamicin80mg/kg B.W)

$\mathrm{C}=$ Alaagool (Fagonia cretica L) 250mg/kg B.W +Gentamicin80mg $/ \mathrm{kg}$ B.W

$\mathrm{D}=$ Alaagool (Fagonia cretica L) 500mg/kg BW +Gentamicin $80 \mathrm{mg} / \mathrm{kg}$ B.W
Serum superoxide dismutase activity (SOD): Table 3 shows changes in super oxide dismutase activity in serum of albino rats treated with (Fagonia spp) Alaagoul extract $(250,500 \mathrm{mg} / \mathrm{kg} \mathrm{B.W}$ ) + gentamicin (80mg/kg B.W- i.p). At day 0 and day 5, there was no significant changes observed in super oxide dismutase (SOD) activity in group B when compared with group (A) the control. At day 10 there was a significant decrease $(p>0.05)$ in the activity of Super oxide ismutase in group B (Gentamicin group) and the level of SOD in group C and D was significantly normalized when compared to the control group.

Table 3: The activity of Superoxide dismutase $(\mathrm{U} / \mathrm{ml})$ in rat's sera samples treated with Fagonia cretica at different doses.

\begin{tabular}{|c|c|c|c|}
\hline Group & Day 0 Mean \pm SE & Day 5 Mean \pm SE & Day 10 Mean \pm SE \\
\hline A & $90.82 \pm 3.22 \mathrm{~b}$ & $92.48 \pm 2.45 \mathrm{a}$ & $92.42 \pm 4.82 \mathrm{c}$ \\
\hline B & $92.13 \pm 1.28 \mathrm{~b}$ & $84.12 \pm 2.34 \mathrm{a}$ & $42.97 \pm 9.66 \mathrm{a}$ \\
\hline C & $79.87 \pm 3.32 \mathrm{a}$ & $93.13 \pm 4.00 \mathrm{a}$ & $62.27 \pm 4.37 \mathrm{ab}$ \\
\hline D & $79.94 \pm 2.33 \mathrm{a}$ & $91.40 \pm 6.03 \mathrm{a}$ & $69.77 \pm 4.53 \mathrm{bc}$ \\
\hline
\end{tabular}

Data are means \pm SE

Means in the same column followed by the same letters are not significantly different at $(p>0.05)$.

$A=$ Negative control

$\mathrm{B}=$ Positive control (Gentamicin80mg/kg B.W)

$\mathrm{C}=$ Alaagool (Fagonia cretica L) 250mg/kg B.W +Gentamicin80mg/kg B.W

$\mathrm{D}=$ Alaagool (Fagonia cretica L) 500mg/kg BW +Gentamicin 80 mg/kg B.W

\section{Discussion}

It was known that antioxidant in foods have many health benefits including prevention of various diseases associated with oxidative stress such as cancer, cardiovascular disease, neuro degeneration and diabetes and others. However, there is a little knowledge of antioxidant activity in a variety of plants. There is strong evidence that reactive oxygen species including free radicals can lead to lipid peroxidation and oxidative stress which damage biological structures such as proteins, lipids and DNA [6]. They result in body ageing and chronic diseases such as heart disease, stroke, certain cancers, neurodegenerative diseases and lung disorders [7]. In 
general, the human body has its own natural antioxidant system to stand against free radicals using certain enzymes. It is believed that an intake of antioxidants reinforces the defense of human antioxidant system. Fruits, vegetables and spices are well known for their natural antioxidants. It has been found that high intake of fruits and vegetables has been associated with lower incidences of chronic diseases such as cancer and heart diseases [8].

\section{Conclusion}

In this study, the administration of Fagonia cretica $L$ ethanolic extract followed by gentamicin improved the activity of catalase and super oxide dismutase. The proximate analysis for the ethanolic extract of Fagonia cretica $L$ demonstrated: The moisture 3.0\%, Ash 14.0\%, protein 27.84\%, Ether extracts 2.3\%, Fiber 19.0\%, Nitrogen free extract $33.86 \%$, Energy 238.6. This result contrast with Veena et al (2014) who reported that the proximate analysis of Fagonia species whole plant exhibited: Moisture $45.12 \%$, Ash $4.59 \%$, Fat $1.22 \%$, Fiber $38.46 \%$, Protein $1.05 \%$, NFE $9.57 \%$ [14]. Found that the Fagonia Arabica whole plant contains: Moisture 45.12\%, Ash $5.59 \%$, Fat $1.22 \%$, Fiber 38.46\%, Protein 1.05, NFE 9.57. Hussain et al (2010) found that Fagonia indica contain: Moisture 11.13\%, Ash 15.68\%, Fat 2.46\%, Fiber 18.69\%, Protein 6.48, Carbohydrate 64.25, Energy 305.06 [15]. Found that the Fagonia cretica contain: Moisture 9.1\%, Ash 11.4\%, Fat 10.1\%, Fiber 40.3\%, Protein 9.8\%, Carbohydrate 19.32\%, Energy 397.8. In this study Moisture content is lower than [14-17]. Ash content is higher than [14-15] findings while it's lower than $[17,18]$ findings. Protein content is higher than [14-17] finding. Fiber content is lower than [14-16] findings while it agrees with [17] findings. Ether extract agree with [17] study while it is higher than $[14,16]$ studies and lower than [15] findings.

\section{Acknowledgment}

None.

\section{Conflict of Interest}

Author declare no conflict of interest.

\section{References}

1. Farnsworth NR, Morris RW (1976) Higher plants the sleeping giant of drug development. Am J Pharm Sci Support Public Health 148(2): 46-45.

2. Rathore MK, Sharma MC, Goyal M, Singh GK, Nagori BP (2011) Pharmacognostical studies on root of Fagonia schweinfurthii Hadidi. International Journal of Pharmaceutical \& Biological Archives 2(5): 1514-1517.
3. Kirtikar KR, Basu BD (1975) In: Indian Medicinal plants. ( $2^{\text {nd }}$ edn), Periodical experts, Delhi, pp. 426-428.

4. Saleh IA, Hasan SY, Aftab A (2011) Anti-inflammantory and wound healing activity of Fagonia schweinfurthi alcoholic extract herbal gel on albino rats. African Journal of Pharmacy and Pharmacology 5(17): 19962001.

5. Decker EA (1998) Antioxidant Mechanisms in Food Lipids. In: CC Akoh, DB Min (Eds.), Marcel Decker, New York, USA, pp. 397-421.

6. Gülçin M, Oktay E, Kreçcı ÖI, Küfrev O (2003) Screening of antioxidant and antimicrobial activities of anise (Pimpinella anisum L.) seed extracts. Food Chemistry 83(3): 371-382.

7. Yildirim AA, Mavi A, Kara AA (2001) Determination of antioxidant and antimicrobial activities of Rumaxs crispus L. extracts. J Agric Food Chem 49(8): 4083-4089.

8. Bravo L (1998) Polyphrnolics: Chemistry, dietary sources, metabolism and nutritional significance. Nutr Rev 56: 317-333.

9. Sukhadev SH, Suman PSK, Gennaro L, Dev DR (2008) An overview of extraction techniques for medicinal and aromatic plants. In: Sukhdev SH (Ed). Extraction technologies for medicinal and aromatic plants. International Center for Science and High Technology, Trieste, Italy.

10. Petterson DS, Harris DJ, Rayner CJ, Blakeney AB, Choct, M (1999) Methods for the analysis of premium livestock grains. Australian Journal of Agricultural Research (50): 775-787.

11. Midkiff V (1984) The history of feed analysis, as chronicled in the development of AOAC official methods, 1884-1984. J Assoc Off Anal Chem (67): 851-860.

12. Lakin AL (1978) Determination of nitrogen and estimation of protein in foods. In: RD King ( $1^{\text {st }}$ edn), Developments in Food Analysis Techniques, Applied Science Publishers, London, p. 43-74.

13. Lodhi GN, Daulat Singh, Ichhponani JS (1976) Variation in nutrient content of feeding stuffs rich in protein and reassessment of the chemical method for metabolizable energy estimation for poultry. Journal of agricultural science (86): 293-303.

14. Shad AA, Shah H, Khattak FK, Dar GN, Bakht J (2002) Proximate and Mineral Constituents of Medicinal Herb Fagonia Arabica. Asian Journal of Plant Sciences 1(6).

15. Dastagir G, Hussain F, Khattak F, Khanzadi (2013) Proximate Analysis of Plants of family Zygophylleacae and Euphorbiaceae During Winter Sarhad J Agri 29(3): 395-400.

16. Veena SK, Seema AG, Jyoti BK, Sharaddha GD (2014) Phytochemical and Biological Evaluation of Fagonia Species: A review World Journal of Pharmacy and Pharmaceutical Sciences 3(5): 1206-1217.

17. Hussain J, Muhammad Z, Ullah R, Khan UF, Rehman N, et al. (2010) Proximate Composition and metal evaluation of four selected medicinal plant species from Pakistan. Journal of Medicinal Plants Research 4(14): 1370-1373.

18. Nanjing Jian Cheng Bioengineering Research Institute, Nanjing, Jiangsu, China. 